Jens P. Janköster

\title{
Fluggastrechte im internationalen Luftverkehr
}

\author{
Verspätung von Fluggästen, Überbuchung und Annullierung von Flügen
}

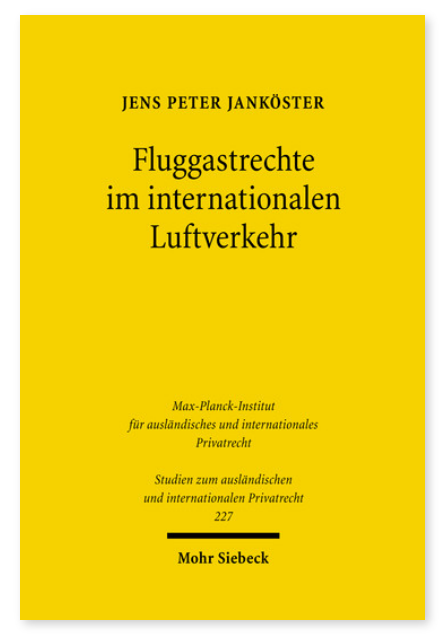

2009. XVIII, 375 Seiten. StudIPR 227

ISBN 978-3-16-151412-8

DOI 10.1628/978-3-16-151412-8

eBook PDF 79,00€

ISBN 978-3-16-150038-1

fadengeheftete Broschur 79,00€
Das gestiegene Verkehrsaufkommen im Luftverkehr führt heute immer häufiger zu Verspätungen von Fluggästen sowie zu Überbuchungen und Annullierungen von Flügen. Jens Peter Janköster untersucht, welche Ansprüche der Fluggast in diesen Situationen gegen den vertraglichen Luftfrachtführer hat.

Dabei stellt sich vor allem die Frage nach der Abgrenzung der Anwendbarkeit von internationalem Einheitsrecht sowie europäischem und nationalem Recht. In diesem Zusammenhang untersucht der Autor insbesondere den häufig angenommenen Fixgeschäftscharakter des Luftbeförderungsvertrages und die Bedeutung der Flugnummer für die Beförderungsverpflichtung des vertraglichen Luftfrachtführers. Insgesamt wird eine tragfähige dogmatische Struktur erarbeitet, die es allen voran der Rechtsprechung ermöglichen soll, nicht nur im Einzelfall sowohl für den Luftfrachtführer als auch für den Fluggast 'gerechte' Lösungen zu finden.

Jens P. Janköster Geboren 1973; Studium der Rechtswissenschaft in Konstanz; 2008 Promotion; derzeit Syndikusanwalt für Reise-, Wettbewerbs- und Kartellrecht bei der Hapag-Lloyd Aktiengesellschaft in Hamburg.

Jetzt bestellen:

https://mohrsiebeck.com/buch/fluggastrechte-im-internationalen-luftverkehr-9783161514128?no_cache=1 order@mohrsiebeck.com

Telefon: $+49(0) 7071-923-17$

Telefax: $+49(0) 7071-51104$ 